\title{
How did food consumption affect architecture?
}

\author{
Annika Seuken ${ }^{1}$ \\ Bachelor Degree of Architecture Study Program \\ Technische Universität Dresden \\ Germany \\ Annika.seuken@gmail.com
}

\begin{abstract}
The essence of this paper is to highlight the cultural differences between two geographically separate cultures. Two aspects are examined: food culture and tourism. In general, as will be shown later in some figures, tourism in Bali and in general will increase steadily. There will be growing new problems and consequences, which I will explain in order to make their dimensions known. Of course, there is also the question of what opportunities this will bring. There will also be insights into the opinions of local Germans and Balinese. I will use the empirical method, i.e. I will look for suitable sources on the basis of my research question. I will use the university network ProQuest and search for keywords, as listed below. I will also search the WordWideWeb for appropriate statistics on the development of tourism to support my theses. My results show that tourism development has two sides, one positive and one negative. It can come to networks between the different nations, continents and cultures, which is naturally a large enrichment on both sides. On the other hand, mass tourism destroys large parts of indigenous nature and culture. The aim is that more and more tourists will be able to come and, little by little, the actual cultural heritage, such as traditional architecture, will be lost.
\end{abstract}

\section{Index Terms - Cultural heritage, cultural differences, food culture, tourism development, traditional archi-tecture.}

\section{INTRODUCTION}

In the Internet, especially on Facebook and Instagram, there is a trend of beautiful restaurants and cafes. Every country has international influences that bring about cultural change. It examines how far Indonesia / Bali has been influenced in terms of food and whether these influences are positive or negative. Are the locals interested in going to these cafes too? Why are these cafes so popular? I don't think this will benefit the locals at all, such as by boosting the economy. I cannot imagine that the emerging economy can play down the whole problem of mass tourism. The culture, daily life and lifestyle of the Indonesians are being lost. This leads to a change, which is mainly caused by tourists.

I have chosen the topic eating cultures and their differences, because when I prepared myself for my journey here I asked myself what kind of differences did I have to come up with? Do you get the same breakfast / lunch / dinner served here every day as in Germany? No, of course not. But I didn't have any clues as to what the food culture of Asia is like, what kind of peculiarities there are and so on. By this term paper I summarize and analyze my observations, which I had in the last 3 months here on Bali, Lombok, Gili Air and Java. 


\section{RESULT AND ANALISYS}

\section{A. Research Process}

First there will be an introduction to the topic of food culture and its influences. It will explain why I chose certain aspects. Afterwards I will have a closer look at the food culture of Indonesia, where I will deal with the peculiarities, rituals and customs. I will do the same with the food culture of Germany to compare two continents / countries and make out whether these two countries even influenced each other. After having dealt extensively with the two countries, I will conduct a short interview with a native German and a native Indonesian to compare my research with personal opinions and experiences. Once I have researched and summarized both countries, I will list and analyze the similarities and differences. Then I will write about food tourism in Indonesia and analyze to what extent it was influenced by Germany and vice versa. Finally there will be a summary and a conclusion of the results.

\section{B. Literature review}

In the course of globalisation, more and more people from different cultures meet every day. A circumstance that opens up significant great opportunities and risks. Often the obvious is forgotten: the cultural differences in thinking and acting of people in different situations. As you can see from the table, Bali is one of the most popular islands in the world (rank 3), which increases tourism and constantly changes the island with its inhabitants. How do you behave when an island lives from tourists and cannot stop them? Exactly, it adapts itself to the wishes and needs of these. It has to be adapted more or less according to the

origin of the tourists, mostly for tourists outside the Asian continent.

Intercontinental, in my opinion, are a few things similar, which is why the adaptation is not too serious. But for Europeans, Australians, Americans and so on, there is a lot to change. From the living situation to the food. Everything is fundamentally different. What exactly has changed and what the traditional and unchanged version of it looks like will be clarified in this paper.

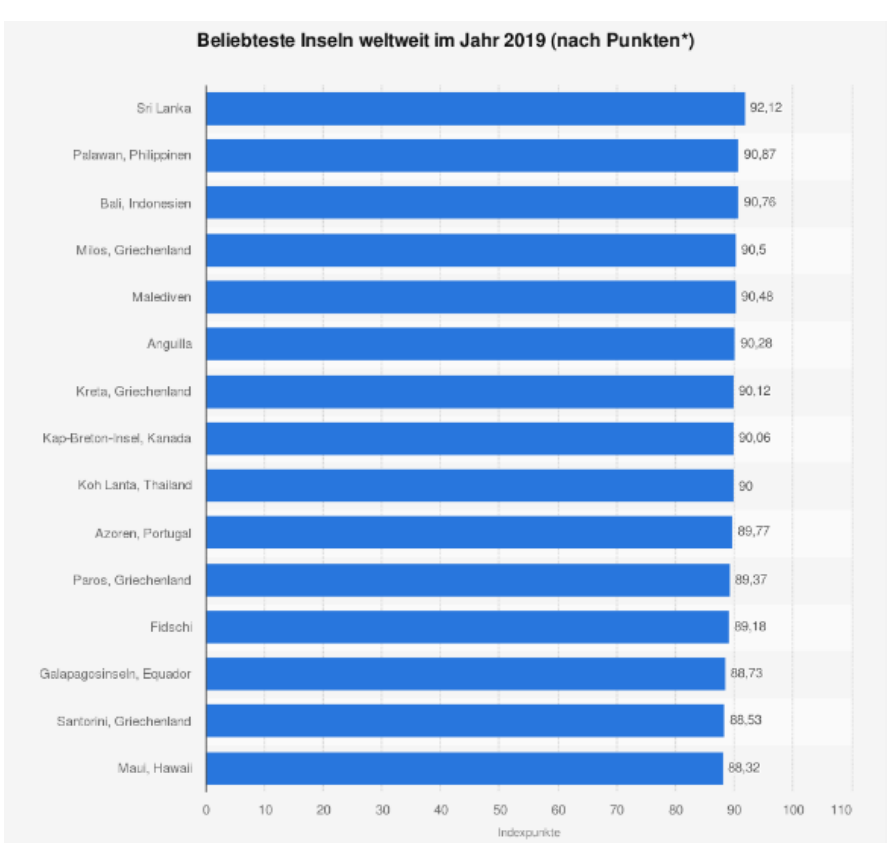

Figure 1 Beliebteste Inseln weltweit im Jahr 2019 (nach Punkten). It shows the importance of Bali in the world for tourists.

\section{Eating / Food culture Indonesia}

Dining in Bali - a culinary expedition

Warungs (street restaurants) and cookshops offer tasty snacks at almost any time of day. The cuisine in Bali is varied and the food is always fresh. In larger towns there are night markets where you can try many specialties from Bali's kitchens. Also in the mornings, warm meals are taken that are freshly pre-cooked by the family for the whole day and thus available the whole day. There are rather no fixed meal times here; everybody eats when he has time and hunger. Thus there is also rarely a (family) meeting, since everyone eats individually.

Origins of Balinese cuisine

Rice has always been the main ingredient of Balinese cuisine, a meal without rice is almost unthinkable. The Balinese cultivate it in large terraced rice fields all over the island. Ginger, turmeric and cardamom came into the country with the Arabian and Indian traders. The Portuguese brought the hot chillies, another main ingredient of Bali's cuisine today. The island owes many sweets and cakes to the influence of the Dutch colonial powers. Refined curries, spicy meat skewers and exotic vegetables are the main ingredients of national dishes such as Gado-Gado, Nasi / Mie Goreng, Nasi Campur, Sate Ayam and many other combinations.

Food: Meaning for the Balinese

Food in Bali means prayer. No food is eaten without being sacrificed on small altars and in ghost houses. Many dishes are specially prepared for religious ceremonies and eaten after the rituals. The elaborate preparation for large ritual celebrations usually lasts several days. Eating and cooking then becomes a social experience. 


\section{Social Aspects: Food rituals and manners}

It is good to know that Indonesians don't talk much or not at all during a meal, but before and after the meal they are all the more talkative. Eating is always done with the right hand, as the left hand is considered unclean, or with a fork and a spoon, knives are never used. When Indonesians eat with chopsticks, they never place them vertically in the food. In Asia, chopsticks stuck vertically in rice are reminiscent of incense sticks lit for the deceased. The chopsticks should therefore always be placed next to the rice bowl. If you are invited to dinner by the locals and selfservice is the order of the day, don't overdo it. If the plate is empty, the host will usually ask you to take a second one. This should not be rejected because such behavior is considered rude in Indonesian culture.

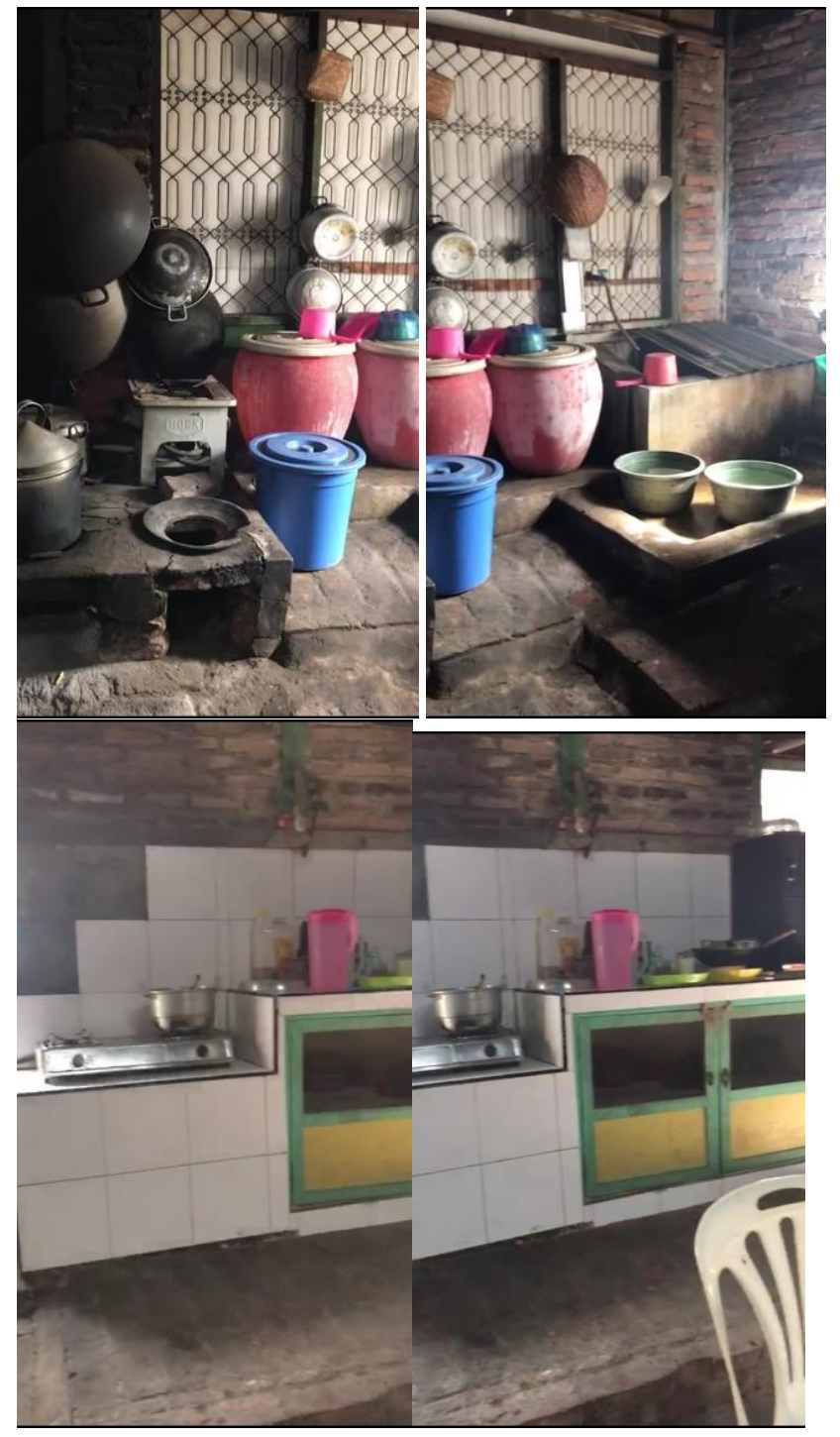

Figure 2. Traditional Paon of a family in West Bali (Photos taken on 2.11.2019)

The unique cuisine (Paon) is very traditional and fundamentally different from that in Germany. The interior of the kitchen is very much based on the Balinese traditions as it still uses firewood for cooking and there is no electricity except for a small lamp. In my opinion, the cuisine reflects the modesty and appreciation of the Balinese tradition, because even if the financial possibility existed, they would not want to change anything.

The true and traditional locals have neither a dining room nor a "real" dining table. Bale Bengong is a bamboo pavilion that is open on all sides. It represents the "dining room" of the Balinese. There are no chairs, because you have to sit on the floor at a small low table. In this Bale you take off your shoes beforehand, as like in many other buildings. In some Bali families the architecture of other countries has prevailed and simple tables and chairs, mostly in the kitchen, can be found where people can eat. Nevertheless, many also eat wherever they want, at the entrance to the house on the step or somewhere in the house. In Indonesia, food is secondary.

\section{E. Survey of a local Indonesia}

1. First, reports of your daily routine related to food.

Here on Bali it is quite different what and when you eat. In the morning I usually eat a snack like fruit or go to the Indomaret where there are small sweet bakery products. When I am very hungry, I get something warm from the numerous street stalls. It's the same at lunchtime and in the evening, with warm food and large quantities being eaten especially in the evening. I also like to go to the Krenneng market in Denpasar, where I meet my friends and siblings. On this market there are normal tables and chairs as you know it from Germany. However, when I eat alone at home, I often sit in front of my room so that I have a beautiful view. With whom do you eat?

2. How did you grow up? Traditional or modern?

I grew up traditionally, which means that my family celebrates and celebrates all traditional and religious festivals. Nevertheless, I was not raised strictly religious, religion is for me nothing strict but something beautiful and unbound.

3. Is there a separate dining room? If No: Where do you eat?

In my family house there is a shared room with kitchen and dining room in one. In the dining room there is a dining table and chairs where we can eat. In my present home I have neither a kitchen nor a dining area, because I usually sit on the floor while eating.

4. How does the preparation of the meal look like?

My mother usually cooks every day early in the morning (she starts at 5:30am), my father never cooks. My father goes to the field and does all the work there and gets some ingredients.

5. What are the three rules to be followed when eating?

- We pray before we eat. We pray basmala Alloohumma barik lanaa fiimaa razaqtanaa waqinaa 'adzaa bannar".

- We eat with the right hand because the left one is the „uncleaned" one.

- We always sit down while we eat. 
6. Are there dishes that are called "Indonesian" but have a different origin?

Some allegedly "typically Indonesian" dishes such as Nasi Goreng or baked goods are originally recipes from Dutch or Chinese people.

7. Have you noticed a change in the cafes in Bali in recent years? If so, what do you think is the reason?

Yes, I noticed a change, but a positive one. Because so many new / strange people come to us in Bali I can find many new friends and make new acquaintances. I like to exchange with them and always learn new things.

8. Are you interested in going to Instagram Cafes or are ordinary restaurants / bars / cafes enough for you?

Yes I'm very interested in going to these cafés! Because inthere are always new people I can meet. I have already made some friends. My younger siblings sometimes do their homework there.

9. Are there similarities between the Instagram restaurants? What is always the same?

I always go to the same restaurants but what I can say about these restaurants is that they always have a very nice ambience. That's probably the intention that as a guest you post pictures of the cafe on the internet and advertise it at the same time. At Instagram all the shops and the food always look very stylish.

10. What are the differences?

In every cafe there are different characteristics. Sometimes there is an especially beautifully designed wall that is very popular, sometimes the food is very special. There is usually a different focus.

\section{F. Food Cultur Germany}

Although it was the Egyptians who were called "bread eaters" in ancient times, today Germany is the nation known worldwide for its diverse and high-quality bread varieties. In Germany people eat a lot of bread, especially dark and wholemeal bread. For breakfast they eat toast or bread rolls, in between a sandwich and in the evening bread with sausage spread or cheese. But you don't always eat bread three times a day. 94 percent of all Germans between the ages of 18 and 69 still eat bread at least once a day. In the mornings and evenings the food usually remains cold, at noon there is something warm and savoury to eat. In some cases, hot meals are also eaten in the evening if the lunch was eaten outside and was rather small. Coffee for breakfast is part of it for many, but one also drinks tea or simply juice or water. Potatoes, whether cooked or fried, are a popular side dish, but meanwhile there is also rice or noodles.

In total, 2.2 billion meals are eaten per week in Germany, an average of four to five eating situations per day are created by every adult 18 years and older. 61 percent of all meals are eaten together, for example with family, friends or colleagues. Remarkably, in 37 percent of all eating situations, the focus is actually on common ground, i.e. you meet with others in order to eat together. Thus, the majority of meals in Germany are taken together. And in over 70 percent of all eating situations, Germans devote themselves entirely to eating. On the other hand, ready-to-eat meals are only purchased for a good fifth of all eating situations. The "to go" trend and the end of eating culture in Germany can thus be refuted.

Fashion and social trends also influence eating culture. The experts are currently observing two such trends in particular. First, there is the reaction to a historical change of our time, globalisation. Industrially produced food is becoming available all over the world, which in turn creates the need for traditional products. They are often advertised as regional, even if they are no longer produced in the region. It should be mentioned that it is often a lot cheaper to cook at home, so for many Germans eating outside is the exception rather than the norm.

\section{G. Social Aspects: Food Rituals and Manners}

Smacking, burping and slurping (unlike in China, for example) is frowned upon in Western culture. It is well known that people do not speak with a full mouth. The body posture should be upright and straight, and the food should be led to the mouth and not the mouth to the plate. Both hands belong on the table - up to the wrist. Only very little food is eaten with the hands, mainly a knife and a fork are used for everything. The spoon is only used for soups.

Architecture

The dining room is usually separate from the kitchen or in the kitchen with a high quality equipment at a high dining table and chairs. The kitchen is well equipped with fridge, dishwasher, microwave and oven. Everything is electronic, there is no need to make a fire.

\section{H. Survey of a local German}

1. First, reports of your daily routine related to food.

In Germany there is a classic breakfast-lunch-dinner, whereby lunch is sometimes the dinner when we are back home late (because of work). When we eat at home, we eat in our dining room at a dining table with chairs and knives and fork. I have breakfast during the week very early in the morning (about half past six in the morning, but I usually have breakfast in the train or at work) and on weekends mostly at about half past eleven. Lunch is served around half past three (very late by German standards). And in the evening there is no fixed time, mostly around seven. For breakfast I eat mostly toast and/or bread with different cold cuts like cheese and sausage and on weekends I eat more elaborate breakfast like yogurt with fruit or strammer max (egg, bread, bacon combination). For lunch in the week mostly faster dishes like noodles with different sauces, casseroles or meat and/or fish with different side dishes. On weekends there is mostly goulash or a roast so dishes that need longer to be prepared. For dinner there is usually only bread or small snacks such as vegetables and fruit.

2. How did you grow up? Traditional or modern?

I grew up modern. A bit religious but everything was left open to me. And I would say that our attitude of faith is also 
"modern", so very relaxed.

3. Is there a separate dining room? If No: Where do you eat?

When I eat at home, we (my mom and me) eat in our dining room at a dining table with chairs. When I eat at work, I eat together with my colleagues at a table with chairs and cutlery.

4. How does the preparation of the meal look like?

Someone from the family goes shopping, the task is never ascribed to just one person, just like cooking. In the past, either mum or dad used to cook (mostly mum because she used to be at home from work early), but since I'm older, I've been cooking a lot too. On weekends, when we eat more elaborate things, my parents do it.

5. What are the three rules to be followed while eating?

It's not appropriate to use a cell phone when you're eating with your family. Besides: don't smack, don't talk with your mouth full, don't eat with your fingers.

6. Are there dishes that are called "German" but have a different origin?

Yes, there are several things. We often eat goulash, which has a Hungarian descent, but for us it belongs to the "German home cooking". Otherwise spaghetti bolognese and pasta in general.

7. Have you noticed a change in the cafes in Germany in recent years? If so, what do you think is the reason?

Yes, there is a much wider range of vegetarian dishes and meanwhile also many vegan dishes. Partly there are also restaurants that are completely vegan or vegetarian, that didn't exist a few years ago.

8. Are you interested in going to Instagram Cafes or are ordinary restaurants / bars / cafes enough for you?

Actually, normal cafés are enough for me, but the instagram cafés are mostly in big cities, so I can combine a visit to these cafés with a day trip. But I could also do without a visit.

9. Are there similarities between the Instagram restaurants? What is always the same?

Yes, there is. The dishes are usually special and fancy, so they look particularly good on pictures, and trendy dishes such as avocado or bowls are also offered. In addition, the furnishings are usually designed in such a way that they invite you to take photos there.

10. What are the differences?

The cafés usually have different concepts. For example: sometimes the food is special and sometimes there are beautifully decorated restaurants. In each one there is a different highlight.

\section{Comparison Indonesian (Bali) with German Food Culture}

- Similarities

At first glance, the two cultures are fundamentally different. Starting with the architecture, which in Bali is very much based on tradition and mostly completely renounces electronics and modernity up to what and when to eat. Nevertheless, there are a few things in common. For example, a place where a table is available is usually visited for eating - sitting down is obligatory. There is a base for every meal - rice or noodles. In addition, every meal is accompanied by vegetables and meat - but in both cultures in different proportions.

\section{- Differences}

As I have already mentioned, both cultures are very different. It turned out that there are some similarities, but the differences are much bigger. In Germany the kitchen and its equipment play a big role because a lot is cooked by the people themselves and a lot of importance is attached to it. It is an exception when eating out or ordering. Therefore a kitchen has to be well organized to make the cooking experience as easy and beautiful as possible. In Indonesia the kitchen plays a big role at ceremonies, because there a big amount of food is produced. Although it is freshly cooked every day, it happens more often that people eat out because it is cheaper than shopping. In Germany you spend a lot more time in the kitchen because you prepare breakfast, lunch and dinner there, while in Indonesia "everything is prepared in one go". I would say that food in Germany is much more influenced by international influences than food in Indonesia. Pizza, pasta, kebab are part of everyday life in Germany, while in Indonesia this is more common in tourist areas. The international influences are limited to the continent.

\section{J. Food Tourism Indonesia}

There are people who decide on where they want to go out to eat by their Instagram feed, and that's a fact that we in the hospitality industry just cannot ignore," said Helen Zhang, director of media strategy at LFB Media Group, a public-relations agency that works with such restaurants as the Stanton Social and Casa Nonna.

The tourism industry has developed into an important source of income and employment for many countries. Bali is ranked 14th among the cities with the highest income from international tourists. It has not risen rapidly since 2017, but it has risen. Due to the increasing tourism, the whole of Bali has to struggle to control the large numbers of international tourists. Over 1000 year old rice terraces are sold and demolished to build huge resorts for the huge rush expected every year. Everything is designed for tourists: Whole island parts are partly only inhabited by tourists, similar to Mallorca where the locals are pushed away bit by bit. Since the bombing in 2002 Bali lost its attractiveness, but since around the last four years the hype is back, this time however in completely different dimensions. The question that is asked: What makes Bali a special place? Of course, it is paradise, but it exists in many other parts of the world. Instagram makes a big contribution to the fact that so many people travel here year after year. It is posted and posted and everyone wants to survive what all the influencers advertise. It is about constant comparison where was I not yet where my role model already was? 
Food can play different roles during a journey. Already Morrison suggested in 2011 that food can be an attribute that attracts tourists to Indonesia Several studies have shown that eating can be a way to experience a new culture and a source of enjoyment. Recent statistical data show that food expenditure is in second place among the total expenditure (18 per cent) of tourists, which represents a significant increase over tourism expenditure in recent years (Euromonitor International, 2012). In my opinion, Instagram Cafes are not much about cultural experience, as there is more international food to meet all tastes. Given the increasing importance of food as a multi-dimensional tourism product, Instagram will play an increasingly important role in this respect.

\section{CONCLUSION}

By this term paper I could summarize and analyze my observations, which I had in the last 3 months here on Bali, Lombok, Gili Air and Java. I think the "good" thing about tourism in Indonesia is that the people are here to get closer to the culture and the people. There is a lot of travel and discovery during the holiday, it is rarely to never a 14-day all inclusive 5 star resort holiday where you can see the hotel complex and nothing else of the rest of the resort.

The bad thing is that the country focuses too much on tourism and ignores its own needs, which could be its downfall. Because if there is no real Indonesia anymore, as it used to be, the tourism quota will drop rapidly. Tourists will look for a new destination and gradually "destroy" it as well, with culture, nature and everything else the country has to offer.

\footnotetext{
REFERENCES

[1] Markus Eidam \& Partner Interkulturelle Trainings, Organisationsentwicklung, Weiterbildung, Dezember 2004
} 